\title{
Power Control Strategies During Voltage Sags According to Spanish Grid Code
}

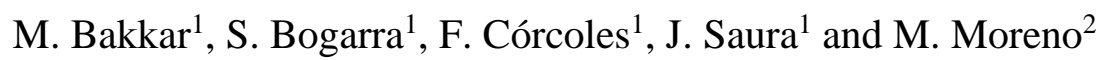 \\ ${ }^{1}$ Department of Electrical Engineering \\ ${ }^{2}$ Department of Electronical Engineering \\ Technical University of Catalonia \\ Colom 1, 08222 Terrassa (Spain) \\ Phone:+0034 93 7398037, e-mail: mostafa.bakkar@upc.edu, bogarra@ee.upc.edu, corcoles@ee.upc.edu, \\ saurap@ee.upc.edu, manuel.moreno.eguilaz@upc.edu
}

\begin{abstract}
In order to connect any power converters into the grid there are some grid requirements to insure the safe operation of the grid. So, the control of the converters especially during abnormal condition-e.g. during voltage sagsis a very important key to guarantee the good behavior of the distributed generation system. In this paper four control strategies, will be stated in the literature, are discussed in order to ensure their ability to match the grid requirements when unsymmetrical voltage sags are produced in the network. The Spanish grid code did not give any information about the negative sequence, and it only represents the positive sequence components. Therefore, the main contribution of this paper is to verify the grid code with not only the positive sequence but also with the negative sequence. Moreover, the system is tested by simulation to show that the results cope well with the analytical equations.
\end{abstract}

\section{Keywords}

Positive and negative sequence controller, voltage sag, voltage ride through, grid code.

\section{Introduction}

Distributed generation systems are becoming a very important part of any grid system. So, the control of the power converters became essential in order to support the grid even under severe transient conditions. Therefore, grid codes become more restrictive recently. Power converters are designed and controlled not only to inject power into the grid during normal conditions, but also to support the grid during transient operation like voltage sags. The converters must remain connected to the grid during the fault and also reduce the active power injection and increase the reactive power injection according to the grid codes.

Most of faults in the grid are unbalanced faults. So, several research is done for controlling the reference current during unbalanced condition in order to inject reactive current to increase positive sequence and to decrease negative sequence voltage components. Different techniques [1-3] discuss the injection of positive and negative sequence currents.

In this paper, four different current control strategies are analyzed in order to study their ability to match the grid code, not only during symmetrical voltage sags but also during unsymmetrical voltage sags.

The organization of the paper is as follows. Section II gives an explanation about the grid code requirements; Section IIIdescribes the different strategies to calculate the reference current. Section IV explains the control techniques under grid code requirements. Finally, Section V shows the simulation results and a comparison between all the presented control techniques, just before the conclusions.

\section{Spanish Grid Code Requirements}

Spanish governments have promoted a sort of legal frameworks regarding grid connection and technical requirements. In 2004, the Spanish government published the RD 436/2004, which was mainly focused on renewable energy sources [4]. In 2006, The Spanish TSO (REE), had approved and issued the requirements for response to voltage dips of production facilities under the special regime (P.O.12.3) [5]. In 2010, the RD 1565/2010 was proposed and issued, [6], this issue was more toward not only wind farms, but also PV power plants. During the fault, renewable energy system must provide the required active and reactive current, in order to support the grid during the voltage sag.In a transient mode, the inverter must be controlled according to the injected active current $\left(I_{\mathrm{a}}\right)$ and reactive current $\left(I_{\mathrm{r}}\right)$ during the fault, according to the network code P.O. 12.2, as shown in Figure 1. 

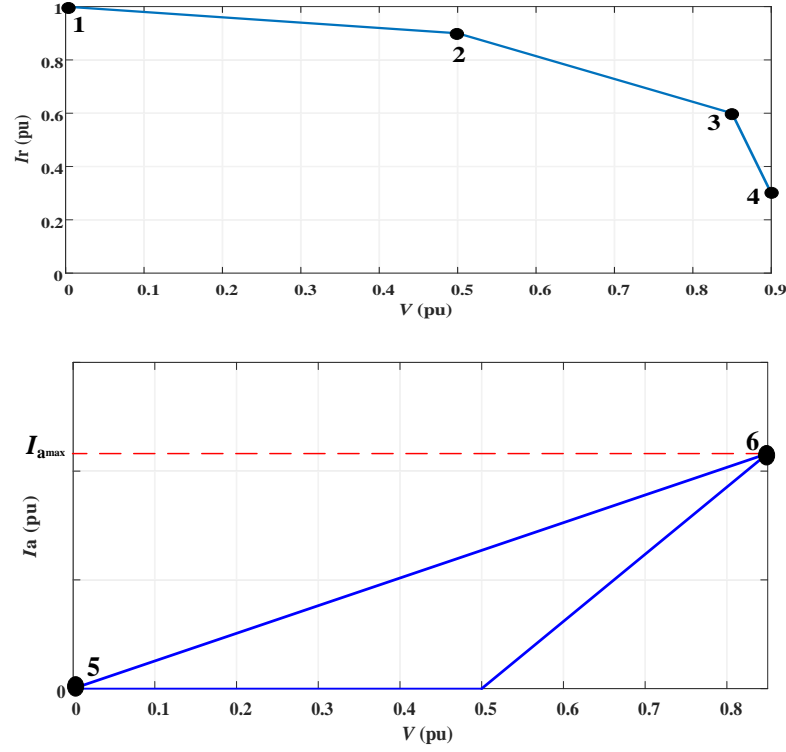

Fig. 1 Active currents $\left(I_{\mathrm{a}}\right)$ and reactive currents $\left(I_{\mathrm{r}}\right)$ to be injected / absorbed during faults, according to Spanish network code P.O. 12.2

In order to describe the magnitude of voltage sag, there is no exact terminology used to describe this. The preferred terminology when describing rms variations is remaining voltage.If the instantaneous three phase rms measurements are used to calculate the grid voltage $V_{1}(t)$ as seen in equation (1), we will have oscillations with amplitudes similar to the negative sequence and harmonic components. This means that filter is needed to obtain a constant value that can be used for further processing [7]. If the phasor values of abc voltages are used, we can obtain a constant voltage value $V_{2}(t)$ without the need of a filter, as seen in equation (2). Equation (2) can be obtained from equation (1) after waveform filtering.

$$
\begin{gathered}
V_{1}(t)=\sqrt{\frac{v_{\mathrm{a}}(t)^{2}+v_{\mathrm{b}}(t)^{2}+v_{\mathrm{c}}(t)^{2}}{3}} \\
V_{2}(t)=\sqrt{\frac{v_{\mathrm{a}}^{2}+v_{\mathrm{b}}^{2}+v_{\mathrm{c}}^{2}}{3 V_{\mathrm{n}}}}
\end{gathered}
$$

Where: $v_{a}(t), v_{b}(t)$, and $v_{c}(t)$ are the instantaneous abc voltage waveform $v_{\mathrm{a}}, v_{\mathrm{b}}$ and $v_{\mathrm{c}}$ are the rms values of the abc voltage waveform $V_{\mathrm{n}}$ is the nominal voltage of the network.

In this paper equation (2) is used to calculate the magnitude of voltage sag. According to this voltage and using Figure 1, the active $\left(I_{\mathrm{a}}\right)$ and reactive $\left(I_{\mathrm{r}}\right)$ currents can be obtained. The maximum active current $I_{\mathrm{amax}}$ depends on the rated values of the converter, so

$$
I_{a \max }=\frac{P_{\mathrm{a} 0}}{1-\Delta V}
$$

Where: $\Delta V$ is the symmetrical voltage ranges around the rated voltage and $P_{\mathrm{a} 0}$ is active power supplied by the installation before the sag.

For the two types of faults -symmetrical and unsymmetrical- the transformed measured voltages have two behaviors. Under symmetrical voltage sag there are no significant oscillations in the transformed voltage, but during unsymmetrical voltage sag the measured voltage oscillates. So, the reference reactive current also oscillates, and also during the voltage sag the value of active current is increase in order to maintain the active power generation. However, the apparent power of the inverter must not exceed its limits. So, the active power must be limited to a value decided by the grid code, in order to maintain connected to the grid during fault period.

\section{Current Control Techniques}

In [8-13] different strategies to determine the references for the current control loops with different control frames have been investigated. In some cases, only positive sequence component is controlled. In this case, the value of active current reference is obtained from the DC-link voltage. On the other hand, the value of reactive current reference is obtained through any independent method such as droop control [14]. In order to solve this issue, positive and negative sequence components is preferred to control the reference current during grid abnormal condition, also it studied the effect of filter on the PI of current control loop. In [15], a positive sequence current injection with feed forward of positive and negative sequence grid voltages is proposed to meet the LVRT requirement. Paper [16] proposes a LVRT control strategy that maximizes the inverter power capability by injecting maximum rated current during the sag. In [17], a strategy to provide both active and reactive power under unbalanced voltage conditions is used.

The power injected into the grid is affected by the positive and negative sequence components produced during the voltage sag. So, if we cannot control the negative sequence of the grid currents, the injected power is oscillating at twice the grid frequency. This control must have the ability to ride through any faults, by increase the injection of reactive power into the grid, and reduce the active power injection during the fault. The main focus in this paper will be the study of the positive and negative dq components, in order to eliminate the oscillation of active and reactive power. The first and second strategies are aim to eliminate the oscillation terms of active and reactive power, 
respectively. The third strategy is aim to inject symmetrical current by imposing a zero values for $\mathrm{dq}$ negative current components. The fourth strategy imposes null values for both terms of power oscillations. Each control technique has some advantages and disadvantages, Table I gives a brief comparison between every control technique showing the merits and demerits of every control technique.

Table I advantages and disadvantages of each control technique

\begin{tabular}{|c|c|c|}
\hline $\begin{array}{c}\text { Control } \\
\text { Technique }\end{array}$ & Advantages & Disadvantages \\
\hline $\mathbf{1}^{\text {st }}$ & $\begin{array}{c}\text { - Instantaneous } \\
\text { reactive power is } \\
\text { constant }\end{array}$ & $\begin{array}{c}\text { - Inject unsymmetrical } \\
\text { sinusoidal current } \\
\text { waves during the sag } \\
\text { - Instantaneous active } \\
\text { power is oscillating }\end{array}$ \\
\hline $\mathbf{2}^{\text {nd }}$ & $\begin{array}{c}\text { - Instantaneous } \\
\text { active power is } \\
\text { constant } \\
\text { sinusoidal current } \\
\text { waves during the sag } \\
\text { - Instantaneous } \\
\text { reactive power is } \\
\text { oscillating }\end{array}$ \\
\hline $\mathbf{3}^{\text {rd }}$ & $\begin{array}{c}\text { - Injects sinusoidal } \\
\text { and symmetrical } \\
\text { current waves } \\
\text { during the sag }\end{array}$ & $\begin{array}{c}\text { - Both instantaneous } \\
\text { active and reactive } \\
\text { power are oscillating }\end{array}$ \\
\hline $\mathbf{4}^{\text {th }}$ & $\begin{array}{c}\text { Both instantaneous } \\
\text { active and reactive } \\
\text { power are constant }\end{array}$ & $\begin{array}{c}\text { - Injects distorted } \\
\text { currents during } \\
\text { voltage sag }\end{array}$ \\
\hline
\end{tabular}

\section{Different Control Techniques Under Grid Code Requirements}

Using the four techniques discussed in Section III, the reference currents are going to be evaluated according to Spanish grid code discussed in Section II. Figure 2 shows graphically the method to calculate the reference currents.

For the four control techniques, the reference positive sequence currents are imposed directly from grid code using equations (4 and 5)

$$
\begin{aligned}
& i_{\mathrm{d} \text { REF }}^{+}=I_{\mathrm{a}} \\
& i_{\mathrm{q} \text { REF }}^{+}=I_{\mathrm{r}}
\end{aligned}
$$

Using the positive reference currents, for every control technique the reference active and reactive power are calculated according to column 3 of Table II.

The calculation of the negative reference currents can be calculated in two cases. The first is by imposing zero negative reference currents, and the second is calculating the negative reference currents using the equations of column 4 of Table II.
The dq sequence currents are calculated by using equations (6 and 7).

$$
\begin{aligned}
& i_{\mathrm{d}}=i_{\mathrm{d}}^{+}+i_{\mathrm{d}}^{-} \cos (2 \omega \mathrm{t})+i_{\mathrm{q}}^{-} \sin (2 \omega \mathrm{t}) \\
& i_{\mathrm{q}}=i_{\mathrm{q}}^{+}+i_{\mathrm{q}}^{-} \cos (2 \omega \mathrm{t})-i_{\mathrm{d}}^{-} \sin (2 \omega \mathrm{t})
\end{aligned}
$$

Where: $i_{\mathrm{d}}^{+}, i_{\mathrm{q}}^{+}, i_{\mathrm{d}}^{-}, i_{\mathrm{q}}^{-}$are $\mathrm{dq}$ positive and negative current components.

In case of imposing zero negative currents, $i_{\mathrm{d}}$ and $i_{\mathrm{q}}$ will not oscillate, otherwise, $i_{\mathrm{d}}$ and $i_{\mathrm{q}}$ will oscillate. The other case, if the negative sequence currents imposed to zero. The verification of grid code for the previous two cases is done by considering that the reactive current $\left(I_{\mathrm{r}}\right)$ relates to $i_{\mathrm{q}}$, and the active current $\left(I_{\mathrm{a}}\right)$ relates to $i_{\mathrm{d}}$. During the faults, the currents $I_{\mathrm{a}}$ and $I_{\mathrm{r}}$ are varied to match with the grid code, so the active and reactive powers will vary [18].

\section{Simulation Results}

To clarify the difference between each control technique and to understand their effects, all these techniques are applied to all sag types and taking into account the sag depth. The results are shown using all strategies with type G sag. Figure 3 shows the voltage, current, instantaneous active and reactive power in pu for $1^{\text {st }}, 2^{\text {nd }}, 3^{\text {rd }}$ and $4^{\text {th }}$ w.r.t. respectively, for type $G$ sag with 0.6 depth. The Figure shows that all the techniques have oscillation in active, reactive power or both, and the only technique that can inject constant power is the $4^{\text {th }}$. However, -as mentioned in section III- $3^{\text {rd }}$ technique has the advantage of injects symmetrical sinusoidal current waves.

If only positive sequence current is imposed (zero negative sequence current) then the four control strategies accomplished the grid code. But, if negative sequence currents are considered (not zero), then the only technique that can satisfy the grid code requirements without any oscillations is the $3^{\text {rd }}$ technique, because the other techniques have oscillation in dq currents, due to the negative components. Figure 4 shows active current, reactive current, active power and reactive power versus sag magnitude in $\mathrm{pu}$.

On the other hand, if it is assumed that the active and reactive grid curves related to power instead of current, then, as shown in Figure 4, the only technique that can gives constant active and reactive power is the $4^{\text {th }}$, however the disadvantage is the bad current control. Figure 4 corresponds to the most unfavorable situation of the grid, so that the following limits are imposed: the upper area of reactive current curve $(1,2,3,4)$, and lower area of active current curve $(5,6)$ shown in Figure 1. In case more priority is given to the reactive power than the active power, this means that $1^{\text {st }}$ 
technique can be a good option, because using this technique reactive power can be controlled without any oscillation as shown in Figure 4, but for active power there are noticeable oscillations.
In order to use $1^{\text {st }}$ technique, active power can be reduced to a lower limit than the upper limit of Figure 1 , so, the oscillation of active power did not exceed the limit of grid code. However, this technique gives sinusoidal unsymmetrical currents.

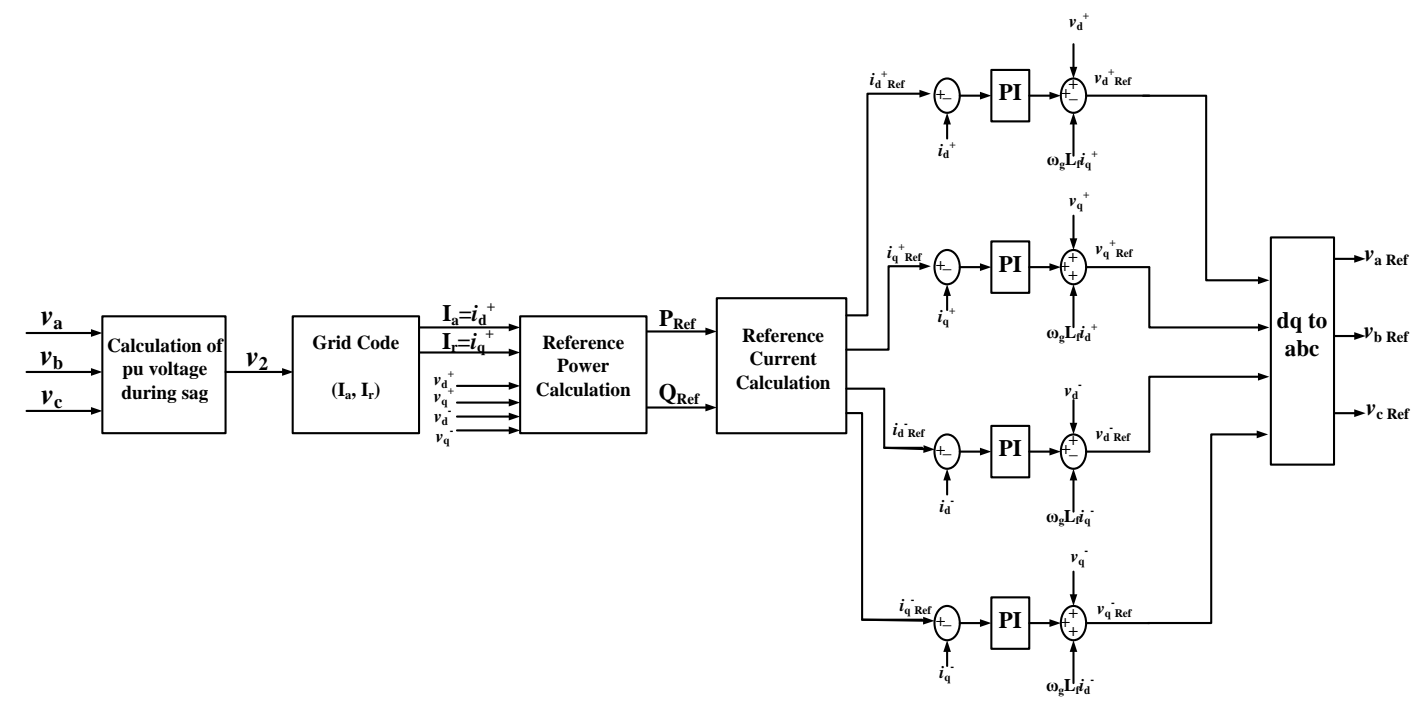

Fig. 2 Calculation of the reference currents taking into account grid code limits

Table II equation of reference active and reactive power, and negative sequence current of control methods mention in previous section according to grid codes.

\begin{tabular}{|c|c|c|c|}
\hline $\begin{array}{l}\text { Control } \\
\text { Method }\end{array}$ & $\begin{array}{c}\text { Positive } \\
\text { Component }\end{array}$ & Reference Active and Reactive Power & Negative Component \\
\hline $1^{\text {st }}$ & $\begin{array}{l}i_{\mathrm{dREF}}^{+}=I_{\mathrm{a}} \\
i_{\mathrm{qREF}}^{+}=I_{\mathrm{r}}\end{array}$ & $\begin{array}{l}P_{\text {REF }}=\frac{\left(v_{\mathrm{d}}^{+2}+v_{\mathrm{q}}^{+2}+v_{\mathrm{d}}^{-2}+v_{\mathrm{q}}^{-2}\right) v_{\mathrm{d}}^{+} I_{\mathrm{a}}}{v_{\mathrm{d}}^{+2}+v_{\mathrm{q}}^{+2}}+\frac{\left(v_{\mathrm{d}}^{+2}+v_{\mathrm{q}}^{+2}+v_{\mathrm{d}}^{-2}+v_{\mathrm{q}}^{-2}\right) v_{\mathrm{q}}^{+} I_{\mathrm{r}}}{v_{\mathrm{d}}^{+2}+v_{\mathrm{q}}^{+2}} \\
Q_{\mathrm{REF}}=\frac{\left(v_{\mathrm{d}}^{+2}+v_{\mathrm{q}}^{+2}-v_{\mathrm{d}}^{-2}-v_{\mathrm{q}}^{-2}\right) v_{\mathrm{q}}^{+} I_{\mathrm{a}}}{v_{\mathrm{d}}^{+2}+v_{\mathrm{q}}^{+2}}-\frac{\left(v_{\mathrm{d}}^{+2}+v_{\mathrm{q}}^{+2}-v_{\mathrm{d}}^{-2}-v_{\mathrm{q}}^{-2}\right) v_{\mathrm{d}}^{+} I_{\mathrm{r}}}{v_{\mathrm{d}}^{+2}+v_{\mathrm{q}}^{+2}}\end{array}$ & $\begin{array}{l}i_{\mathrm{dREF}}^{-}=\frac{\left(v_{\mathrm{d}}^{+} v_{\mathrm{d}}^{-}-v_{\mathrm{q}}^{+} v_{\mathrm{q}}^{-}\right) i_{\mathrm{d}}^{+}}{v_{\mathrm{d}}^{+2}+v_{\mathrm{q}}^{+2}}+\frac{\left(v_{\mathrm{d}}^{+} v_{\mathrm{q}}^{-}+v_{\mathrm{q}}^{+} v_{\mathrm{d}}^{-}\right) i_{\mathrm{q}}^{+}}{v_{\mathrm{d}}^{+2}+v_{\mathrm{q}}^{+2}} \\
i_{\mathrm{q} \text { REF }}^{-}=\frac{\left(v_{\mathrm{d}}^{+} v_{\mathrm{q}}^{-}+v_{\mathrm{q}}^{+} v_{\mathrm{d}}^{-}\right) i_{\mathrm{d}}^{+}}{v_{\mathrm{d}}^{+2}+v_{\mathrm{q}}^{+2}}+\frac{\left(-v_{\mathrm{d}}^{+} v_{\mathrm{d}}^{-}+v_{\mathrm{q}}^{+} v_{\mathrm{q}}^{-}\right) i_{\mathrm{q}}^{+}}{v_{\mathrm{d}}^{+2}+v_{\mathrm{q}}^{+2}}\end{array}$ \\
\hline $2^{\text {nd }}$ & $\begin{array}{l}i_{\mathrm{dREF}}^{+}=I_{\mathrm{a}} \\
i_{\mathrm{qREF}}^{+}=I_{\mathrm{r}}\end{array}$ & $\begin{array}{l}P_{\text {REF }}=\frac{\left(v_{\mathrm{d}}^{+2}+v_{\mathrm{q}}^{+2}-v_{\mathrm{d}}^{-2}-v_{\mathrm{q}}^{-2}\right) v_{\mathrm{d}}^{+} I_{\mathrm{a}}}{v_{\mathrm{d}}^{+2}+v_{\mathrm{q}}^{+2}}+\frac{\left(v_{\mathrm{d}}^{+2}+v_{\mathrm{q}}^{+2}-v_{\mathrm{d}}^{-2}-v_{\mathrm{q}}^{-2}\right) v_{\mathrm{q}}^{+} I_{\mathrm{r}}}{v_{\mathrm{d}}^{+2}+v_{\mathrm{q}}^{+2}} \\
Q_{\mathrm{REF}}=\frac{\left(v_{\mathrm{d}}^{+2}+v_{\mathrm{q}}^{+2}+v_{\mathrm{d}}^{-2}+v_{\mathrm{q}}^{-2}\right) v_{\mathrm{q}}^{+} I_{\mathrm{a}}}{v_{\mathrm{d}}^{+2}+v_{\mathrm{q}}^{+2}}-\frac{\left(v_{\mathrm{d}}^{+2}+v_{\mathrm{q}}^{+2}+v_{\mathrm{d}}^{-2}+v_{\mathrm{q}}^{-2}\right) v_{\mathrm{d}}^{+} I_{\mathrm{r}}}{v_{\mathrm{d}}^{+2}+v_{\mathrm{q}}^{+2}}\end{array}$ & $\begin{array}{l}i_{\mathrm{dREF}}^{-}=\frac{\left(-v_{\mathrm{d}}^{+} v_{\mathrm{d}}^{-}+v_{\mathrm{q}}^{+} v_{\mathrm{q}}^{-}\right) i_{\mathrm{d}}^{+}}{v_{\mathrm{d}}^{+2}+v_{\mathrm{q}}^{+2}}+\frac{\left(-v_{\mathrm{d}}^{+} v_{\mathrm{q}}^{-}-v_{\mathrm{q}}^{+} v_{\mathrm{d}}^{-}\right) i_{\mathrm{q}}^{+}}{v_{\mathrm{d}}^{+2}+v_{\mathrm{q}}^{+2}} \\
i_{\mathrm{q} \text { REF }}^{-}=\frac{\left(-v_{\mathrm{d}}^{+} v_{\mathrm{q}}^{-}-v_{\mathrm{q}}^{+} v_{\mathrm{d}}^{-}\right) i_{\mathrm{d}}^{+}}{v_{\mathrm{d}}^{+2}+v_{\mathrm{q}}^{+2}}+\frac{\left(v_{\mathrm{d}}^{+} v_{\mathrm{d}}^{-}-v_{\mathrm{q}}^{+} v_{\mathrm{q}}^{-}\right) i_{\mathrm{q}}^{+}}{v_{\mathrm{d}}^{+2}+v_{\mathrm{q}}^{+2}}\end{array}$ \\
\hline $3^{\text {rd }}$ & $\begin{array}{l}i_{\mathrm{d} \text { REF }}^{+}=I_{\mathrm{a}} \\
i_{\mathrm{q} \mathrm{REF}}^{+}=I_{\mathrm{r}}\end{array}$ & $\begin{array}{l}P_{\mathrm{REF}}=v_{\mathrm{d}}^{+} I_{\mathrm{a}}+v_{\mathrm{q}}^{+} I_{\mathrm{r}} \\
Q_{\mathrm{REF}}=v_{\mathrm{q}}^{+} I_{\mathrm{a}}-v_{\mathrm{d}}^{+} I_{\mathrm{r}}\end{array}$ & $\begin{array}{l}i_{\mathrm{dREF}}^{-}=0 \\
i_{\mathrm{qREF}}^{-}=0\end{array}$ \\
\hline $4^{\text {th }}$ & $\begin{array}{l}i_{\mathrm{d} \text { REF }}^{+}=I_{\mathrm{a}} \\
i_{\mathrm{q} \text { REF }}^{+}=I_{\mathrm{r}}\end{array}$ & $\begin{array}{l}P_{\mathrm{REF}}=\frac{v_{\mathrm{mod}}^{2}}{v_{\mathrm{d}}^{2}+v_{\mathrm{q}}^{2}}\left(v_{\mathrm{d}}^{+} I_{\mathrm{a}}+v_{\mathrm{q}}^{+} I_{\mathrm{r}}\right) \\
Q_{\mathrm{REF}}=\frac{v_{\mathrm{mod}}^{2}}{v_{\mathrm{d}}^{2}+v_{\mathrm{q}}^{2}}\left(v_{\mathrm{q}}^{+} I_{\mathrm{a}}-v_{\mathrm{d}}^{+} I_{\mathrm{r}}\right)\end{array}$ & $\begin{array}{l}i_{\mathrm{d} \text { REF }}^{-}=\frac{1}{v_{\text {mod }}^{+} 2}\left(v_{\mathrm{d}}^{-} P_{\mathrm{REF}}+v_{\mathrm{q}}^{-} Q_{\mathrm{REF}}\right) \\
i_{\mathrm{q} \text { REF }}^{-}=\frac{1}{v_{\mathrm{mod}}^{+} 2}\left(v_{\mathrm{q}}^{-} P_{\mathrm{REF}}-v_{\mathrm{d}}^{-} Q_{\mathrm{REF}}\right)\end{array}$ \\
\hline
\end{tabular}


In order to inject sinusoidal symmetrical current during voltage sag, the only technique to obtain this is the $3^{\text {rd }}$ technique. On the other hand, active and reactive power have an oscillation. So, by using $3^{\text {rd }}$ technique it is necessary to reduce the active and reactive power to different limits below the limit of active power and above the limit of reactive power.

Table III shows the difference between every control technique.
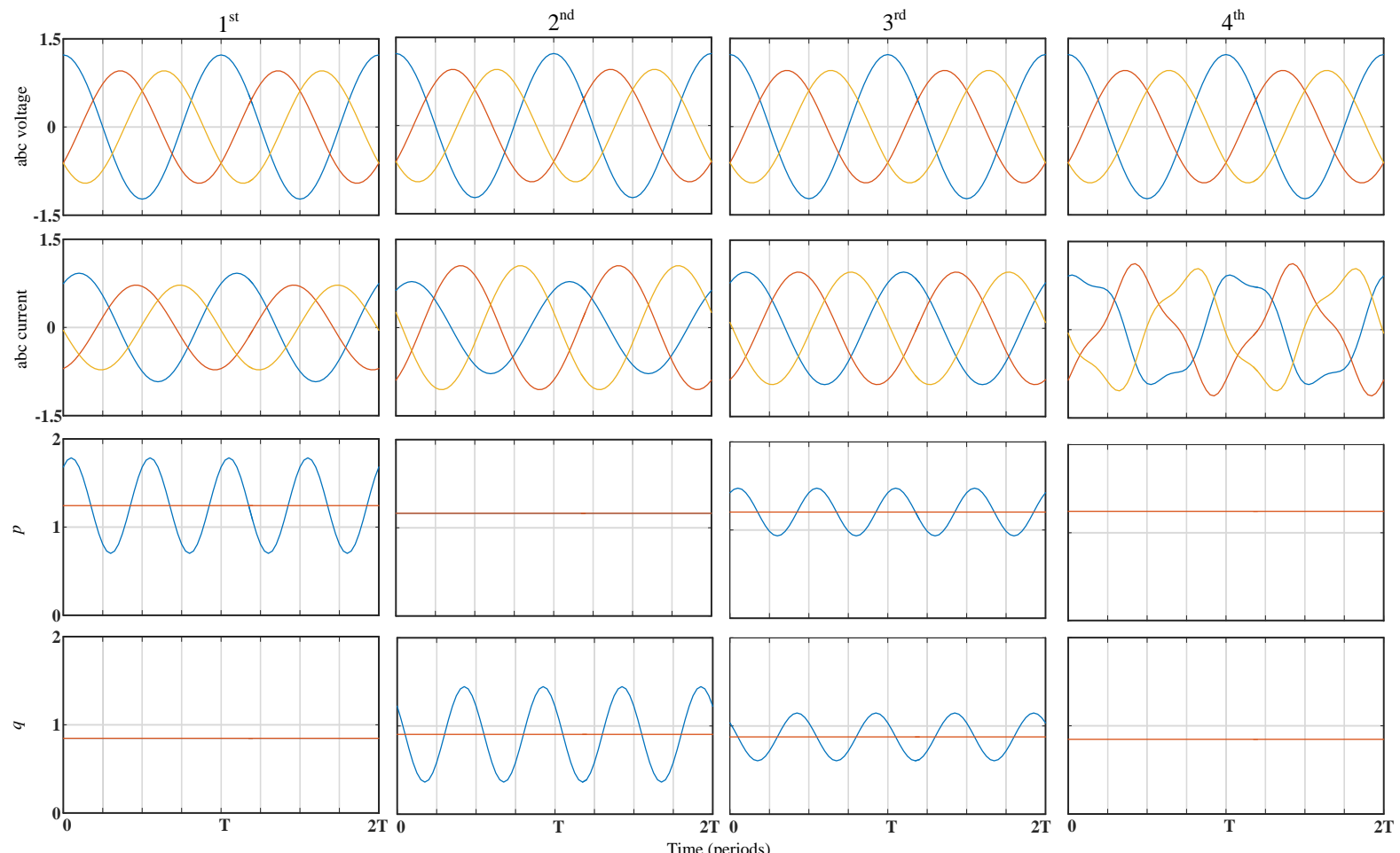

Fig.3 Type G sag under different control Techniques
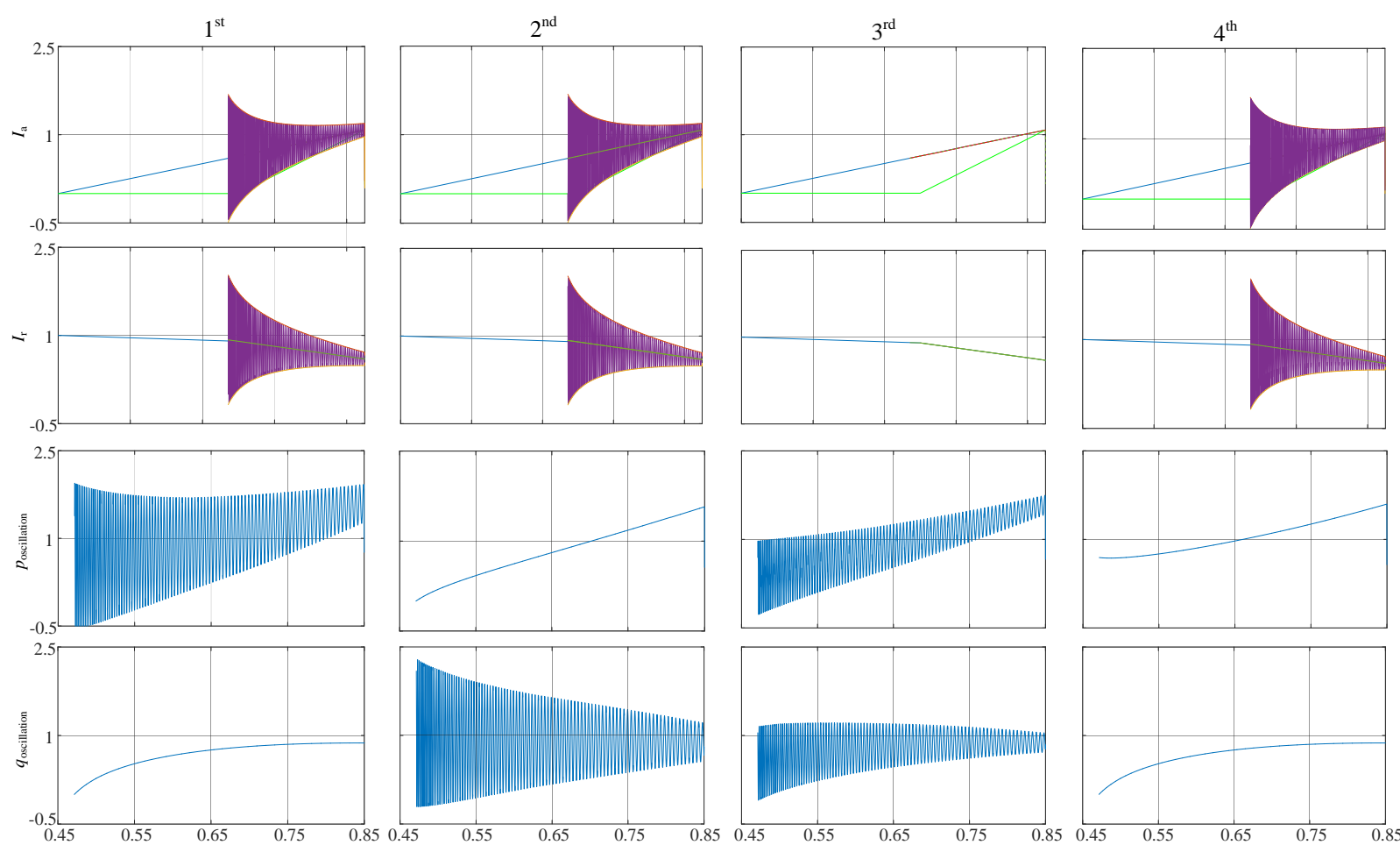

Fig .4 active and reactive currents and powers in pu with different control strategies 
Table III behavior of each control technique

\begin{tabular}{|c|r|r|r|r|r|r|}
\hline $\begin{array}{c}\text { Control } \\
\text { Technique }\end{array}$ & GCV & GPV & SICW & SYCW & p(t) & q(t) \\
\hline $\mathbf{1}^{\text {st }}$ & $\times$ & $\times$ & $\checkmark$ & $\times$ & $\times$ & $\checkmark$ \\
\hline $2^{\text {nd }}$ & $\times$ & $\times$ & $\checkmark$ & $\times$ & $\checkmark$ & $\times$ \\
\hline $3^{\text {rd }}$ & $\checkmark$ & $\times$ & $\checkmark$ & $\checkmark$ & $\times$ & $\times$ \\
\hline $\mathbf{4}^{\text {th }}$ & $\times$ & $\checkmark$ & $\times$ & $\times$ & $\checkmark$ & $\checkmark$ \\
\hline
\end{tabular}

GCV - Grid code current verification, GPV - Grid code power verification, SICW - Sinusoidal current waves, SYCW - Symmetrical current waves, $\mathrm{p}(\mathrm{t})$ instantaneous active power, and $\mathrm{q}(\mathrm{t})$ instantaneous reactive power.

\section{Conclusion}

In order to control the active and reactive power during abnormal behavior of the grid, it is mandatory to control the positive and negative reference currents. In this paper, different control techniques during voltage sags are studied. Moreover, in order to verify the Spanish grid code using these strategies two cases are considered: first, only positive sequence current is imposed, and second, positive and negative sequence current are imposed.

The results show that, in order to inject the most unfavorable situation of the grid, $3^{\text {rd }}$ technique is the only technique that can gives the exact required limits of active and reactive currents. However, it has the disadvantage of power oscillation. On the other hand, $4^{\text {th }}$ technique can verify the grid code if we assume that the grid code curves related to active and reactive power instead of currents. Moreover, other controls can be used with proper limits in order not to breaching the grid codes.

\section{References}

[1] L.Kuang, L. Jinjun, W. Zhaoan, W. Biao, "Strategies and Operating Point Optimization of STATCOM Control for Voltage Unbalance Mitigation in Three-Phase Three-Wire Systems," IEEE Trans. on Power Delivery, vol. 22, no. 1, pp. 413-422, Jan. 2007.

[2] Castilla, M.; Miret, J.; Camacho, A.; Matas, J.; Garcia de Vicuna, L. "Voltage Support Control Strategies for Static Synchronous Compensators Under Unbalanced Voltage Sags", IEEE Trans. Ind. Electron, vol. 61, no. 2, pp. 808820, Feb. 2014

[3] R. Teodorescu, M. Liserre, and P. Rodriguez, Grid Converters for Photovoltaic and Wind Power Systems. , USA: John Wiley \& Sons, ch.10, pp.237-288, 2011.

[4] Royal Decree 436/2004, 12 of March, "Por el que se establece la metodología para la actualización y sistematización del régimen jurídico y económico de la actividad de producción de energíaeléctricaen régimen especial".

[5] BOE no 254. "Resolución de 4 de octubre de 2006, de la secretara general de energía, por la que se aprueba el procedimiento de operación 12.3 requisitos de respuesta frente a huecos de tensión de las instalaciones eólicas”. 24 of October 2006.
[6] Royal Decree 1565/2010, November 19, "Por el que se regulan y modificandoterminadosaspectosrelativos a la actividad de producción de energíaeléctrica enrégimen especial",

[7] Math H. J. Bollen, Irene Yu-Hua Gu, Signal Processing of Power Quality Disturbances Wiley-IEEE Press., 2006.

[8] T. Lee, S. Hu, and Y. Chan, "D-STATCOM with positivesequence admittance and negative-sequence conductance to mitigate voltage fluctuations in high-level penetration of distributed generation systems," IEEE Trans. Ind. Electron., vol. 60, no. 4, pp. 1417-1428, Apr. 2013.

[9] P. Rodriguez, G. Medeiros, A. Luna, M. C. Cavalcanti, and R. Teodorescu, "Safe current injection strategies for a STATCOM under asymmetrical grid faults," in Proc. IEEE ECCE, pp. 3929-3935, 2010.

[10] M. T. Bina and M. D. Eskandari, "Consequence of unbalance supplying condition on a distribution static compensator," in Proc. IEEE 35thAnnu.Power Electron. Spec. Conf., vol. 5, pp. 3900-3904, 2004.

[11] S. Babaei, B. Fardanesh, S.Bhattacharya, "High-Power VSC-based simultaneous positive and negative sequence voltage regulator", IEEE Trans. Power Del., vol. 29, no. 5, pp. 2124-2135, Oct. 2014

[12] R. Teodorescu, M. Liserre, and P. Rodriguez, Grid Converters for Photovoltaic and Wind Power Systems, USA: John Wiley \&Sons, ch.10, pp.237-288, 2011.

[13] M. Mirhosseini, J. Pou, B. Karanayil and V. G. Agelidis, "Positive- and Negative-Sequence Control of GridConnected Photovoltaic Systems under Unbalanced Voltage Conditions", Power Engineering Conference (AUPEC), 2013 Australasian Universities, , pp. 1-6, oct. 2013.

[14] R. Kabiri, D. G. Holmes and B. P. McGrath, "Double Synchronous Frame Current Regulation of Distributed Generation Systems under Unbalanced Voltage Conditions without Sequence Current Separation", Applied Power Electronics Conference and Exposition (APEC), 2015 IEEE, NC, USA, March, 2015.

[15] P. Zhang, G. Zhang, H. Wang, "Control Strategy of Low Voltage Ride-Through for Grid-Connected Photovoltaic Inverter", Power Electronics for Distributed Generation Systems (PEDG), 2015 IEEE 6th International Symposium on, Aachen, Germany, June 2015.

[16] J. Sosa, M. Castilla, J. Miret, J. Matas, and Y. A. AlTurki, "Control Strategy to Maximize the Power Capability of PV Three-Phase Inverters During Voltage Sags", IEEE Transactions on Power Electronics, vol. 31, no. 4, April 2016.

[17] A. Khoshooei, J. S. Moghani, J. Milimonfared, A.Luna, I. Candela and P. Rodriguez, "Control of D-STATCOM During Unbalanced Grid Faults Based on DC Voltage Oscillations and Peak Current Limitations", Energy Conversion Congress and Exposition (ECCE), 2016 IEEE, WI, USA, Sept. 2016.

[18] Red Eléctrica de España, "Requisitos técnicos de las instalaciones eólicas, fotovoltaicas y todas aquellas instalaciones de producción cuya tecnología no emplee un generador síncrono conectado directamente a la red", Separata del borrador de P.O. 12.2 "Instalaciones conectadas a la Red de Transporte y equipo generador: requisitos mínimos de diseño, equipamiento, funcionamiento, puesta en servicio y seguridad", octubre de 2008. 